\title{
Comunicação Comunitária e Educação para a Cidadania*
}

\section{Cicilia M.Krohling Peruzzo**}

\section{Resumo:}

O texto trata da edu-comunicação forjada num processo de educação informal e no contexto das organizações e movimentos populares. Conclui-se que, na prática, com características próprias, entre elas a da participação ativa e dos conteúdos condizentes com as realidades locais, a comunicação produzida por setores subalternos organizados vem contribuindo para ampliar o espectro em torno do exercício da cidadania.

Palavras-chave: comunicação e cidadania, comunicação comunitária e cidadania, educação e cidadania.

\section{Introdução}

Os estudos sobre comunicação e educação tendem a enfocar as relações e as inter-relações entre os dois campos do conhecimento, principalmente a questão do ensino-aprendizagem enquanto mediada por um processo comunicativo; da utilização de meios de comunicação na educação presencial, nas instituições de ensino; do papel da mídia no processo de educação; da educação para a recepção crítica das mensagens transmitidas através dos meios massivos, especialmente da televisão. Trata-se de uma linha de estudos em expansão e que tem trazido contribuições significativas para a compreensão de tais fenômenos; no entanto, ainda não é suficientemente compreendida e valorizada pelos educadores e comunicadores.

* Texto apresentado no V Simpósio de Pesquisa em Comunicação do Centro-Oeste, realizado em Goiânia, entre 20 a 22/05/99.

** Professora Doutora da Universidade Metodista de São Paulo (UMESP).

Comun. Inf., v. 2, n. 2, p. 205-228, jul./de\%. 1999 
Este estudo baliza-se em outra perspectiva diferente das mencionadas acima. Tratamos da edu-comunicação forjada em outro lugar, no âmbito da educação informal, mais precisamente a que ocorre no contexto de organização e ação das organizações e movimentos populares e ONGs - Organizações não Governamentais, no âmbito do terceiro setor, quando as pessoas se mobilizam, se organizam ou se envolvem em organizações já existentes para assegurar a observância dos direitos fundamentais da pessoa humana e/ou para tratar de temática sociais mais amplas, que dizem respeito ao conjunto da sociedade, como, por exemplo, questões relativas à ecologia, à construção da paz e da própria vida no planeta.

Nas últimas décadas, manifestações de tal ordem, ocorridas em nível da sociedade civil, vêm revelando a existência de uma comunicação diferenciada, a partir dos envolvimentos acima referidos, principalmente aqueles gerados no seio das camadas subalternas da população, ou a elas ligados de modo orgânico. As pessoas, ao participarem de uma práxis cotidiana voltada para os interesses e necessidades dos próprios grupos a que pertencem ou ao participarem de organizações e movimentos comprometidos com interesses sociais mais amplos, acabam inseridas num processo de educação informal que contribui para a elaboraçãoreelaboração das culturas populares e formação para a cidadania.

Esse tipo de manifestação organizativa-cultural tem sido extremamente forte no Brasil e na América Latina, dadas as peculiaridades desses países, nos quais a grande maioria da população é excluída das benesses do desenvolvimento, e onde se verificam grandes transformações sociais nos últimos vinte anos.

Este estudo baseia-se em pesquisa bibliográfica sobre o papel político dos movimentos sociais, sem relatos de estudos de casos de experiências de comunicação popular/comunitária participativa e em observação participante junto a movimentos populares e numa rádio comunitária no estado do Espírito Santo, Brasil.

Comun. Inf., v. 2, n. 2, p. 205-228, jul./de\%. 1999 


\section{As dimensões da cidadania}

Para melhor compreendermos a questão da educação para a cidadania advinda dos processos de envolvimento das pessoas nos meios de comunicação comunitários, vamos situar, brevemente, o que entendemos por cidadania.

Em direito internacional, cidadania diz respeito à nacionalidade: o direito de pertencer à uma nação. Para além dessa noção, cidadania incorpora a garantia de se ter: a) proteção legal - na perspectiva da igualdade, como a de que todos são iguais perante a lei; b) o direito de locomover-se - ir de um lugar para o outro livremente; c) participação política - votar e ser votado, interferir na vida política; d) direito de expressão.

Em sua essência, cidadania funda-se em concepções de sociedade e, como tal, são essas concepções que orientam a cidadania ${ }^{1}$.

$\mathrm{Na}$ concepção liberal há uma individualização da cidadania. E uma separação entre as esferas pública e privada. O que conta é o indivíduo, os direitos da pessoa individualmente. A busca central é a satisfação do interesse próprio, particular. O modelo liberal "desaconselha a ação social e política, com base na concepção de que apenas a ação econômica privada pode conduzir ao bem-estar coletivo. A personalidade do cidadão era absorvida pela 'personalidade' do produtor e trocador de mercadorias" (Abranches, 1985, p.9).

Uma outra concepção de cidadania, desenvolvida por Rousseau, no século XVIII, é originária da noção grega de "polis" (cidade), derivado de "politikos" (político = ser social). Nesta perspectiva, cidadania é vista como um direito coletivo que, favorecendo o desenvolvimento da individualidade, pressupõe a ação política e sua socialização. Tendo como suporte uma legislação que procura levar em conta os princípios de igualdade e de liberdade, ela implica não só em direitos do indivíduo, mas também seus deveres na sociedade.

"A 'polis' integralmente constituída correspondia a uma sociedade politizada, na qual a esfera pública ocupava um território

Comun. Inf., v. 2, n. 2, p. 205-228, jul./ dez. 1999 


\section{8}

mais amplo nas vidas dos cidadãos e estava situada num plano muito mais elevado de importância do que os assuntos privados dos indivíduos. (...) A 'polis' baseava-se na ação coletiva, portanto, na liberdade coletiva. A cidadania refletia a integração do indivíduo à coletividade política" (Abranches, 1985, p.9).

Conforme esclarece Barbalet (1989, p.11-2), a cidadania encerra manifestadamente uma dimensão política, mas a prática mostra que isto não é suficiente para que ela seja compreendida. O problema está em quem pode exercê-la e em que termos é exercida. A questão está, de um lado, na cidadania como direito e, de outro, na incapacitação política dos cidadãos, em razão do grau de domínio dos recursos sociais e de acesso a eles. Por exemplo, da ágora grega não participavam escravos, mulheres e metekes (estrangeiros). No Brasil, a mulher e os analfabetos só adquiriram o direito de votar em 1934 e em 1988, respectivamente. Assim, dependendo do período histórico e do país ou lugar, só uma parcela da população pode exercer plenamente a cidadania.

A conquista da cidadania significa a passagem de súditos para cidadãos, cujo arcabouço social requer o envolvimento das pessoas, condicionando-se seu status de cidadão à qualidade da participação. Esta é uma de suas bases. Outra está na noção de que suas formas se condicionam ao tipo de sociedade política em que se vive. "Estes princípios foram enunciados há quase dois mil e quinhentos anos, no terceiro livro da obra "Política", de Aristóteles. A principal diferença entre a cidadania nas cidadesestados gregas e no moderno Estado democrático é a extensão do âmbito da comunidade política em cada um deles. "Para Aristóteles, cidadania era o 'status' privilegiado do grupo dirigente da cidade-estado. No Estado democrático moderno, a base da cidadania é a capacidade de participar no exercício do poder político por meio do processo eleitoral. (...) Para Aristóteles, o 'status' da cidadania estava limitado aos autênticos participantes nas deliberações e no exercício do poder. Presentemente, a cidadania nacional estende-se a toda a sociedade" (Barbalet, 1989, p.12-13).

Comun. Inf., v. 2, n. 2, p. 205-228, jul./dez. 1999 
Não obstante, o status de cidadão é uma construção social que vem se modificando ao longo da história, numa extensão que varia conforme os países. Na sociedade moderna, os cidadãos são membros de uma sociedade política baseada no sufrágio universal e na qual todos são considerados iguais perante a lei. $O$ que nem sempre ocorre na prática. No caso do Brasil e de outros países latino-americanos, por exemplo, o direito à propriedade que é básico do próprio modo de produção capitalista, o direito à educação etc., assegurados legalmente, são negados, na prática, à maioria $\mathrm{da}$ população.

Há que se levar em conta, também, as diferenças entre cidadania e direitos humanos, ou direitos do cidadão. Como diz Moretti (1999, p.60), cidadania é regulada pelo Estado e pode variar de uma sociedade para outra. Já os direitos humanos são universais e históricos, extrapolam os limites de uma nação. Exemplo: o direito à moradia $\mathrm{e}$ a $\mathrm{o}$ acesso ao conhecimento.

Na perspectiva de Marshall (1967, p.63-64), a cidadania incorpora três tipos de direitos: os civis, os políticos e os sociais. $\mathrm{O}$ elemento civil é composto dos direitos necessários à liberdade individual: liberdade de ir e vir, liberdade de expressão, pensamento $\mathrm{e}$ fé, $\mathrm{o}$ direito à propriedade $\mathrm{e} \mathrm{o}$ direito à justiça. Tais direitos estão sob a alçada do poder judiciário. Por elemento político da cidadania deve-se entender o direito de participar do exercício do poder político, como membro de um organismo investido de autoridade política ou como eleitor de tais membros. As instituições correspondentes são o parlamento e os conselhos do Governo local. O elemento social da cidadania refere-se a tudo o que vai desde o direito a um mínimo de bem-estar econômico e segurança, ao direito de participar na herança social e levar a vida de um ser civilizado de acordo com os padrões que prevalecem na sociedade. As instituições mais ligadas a ele são os sistemas educacionais e de serviços sociais.

Em suma, cidadania inclui: a) direitos no campo da liberdade individual: liberdade, igualdade, locomoção e justiça; b) direitos de participação no exercício do poder político: participação política em todos os níveis: eleições, plebiscitos, participação em

Comun. Inf., v. 2, n. 2, p. 205-228, jul./dez. 1999 


\section{0}

órgãos de representação, tais como sindicatos, movimentos e associações; c) direitos sociais: direito e igualdade de usufruto de um modo de vida digno, através do acesso ao patrimônio social, ligado ao consumo, ao lazer, condições e leis do trabalho, à moradia, à educação, à saúde, à aposentadoria etc.

Os direitos civis e políticos são chamados de direitos de primeira geração, os sociais de segunda geração. "Na segunda metade do século XX surgiram os direitos de terceira geração, que têm como titular não o indivíduo, mas os grupos humanos, como o povo, a nação, coletividades étnicas, minorias discriminadas e até o direito de autodeterminação dos povos. A onde têm desenvolvidos $[s i c]$ em conferências mundiais os direitos humanos, o direito das mulheres, o direito ao desenvolvimento, direito à paz, direito ao meio ambiente. Entre esses direitos da terceira geração estariam também os dos 'novos movimentos sociais', como direitos relativos a interesses difusos, direito do consumidor, direito à ecologia, direito à qualidade de vida, direito da terceira idade, direito das crianças, dos jovens etc. Entre estes direitos colocamos o direito à participação popular no orçamento municipal e direitos à cidade, direitos ao pluralismo e às diferenças" (Krohling, 1997, p.118).

Finalmente, queremos ressaltar algumas noções fundamentais que encerram a questão da cidadania. Primeiro: o cidadão tem direitos e deveres. A participação política, a responsabilidade pelo conjunto da coletividade, o cumprimento das normas de interesse público, são deveres, por exemplo. Segundo: cidadania é histórica. Varia no tempo e no espaço, varia conforme o período histórico e o contexto vivido. Portanto, cabe sempre perguntar quem pode exercer plenamente a cidadania. Terceiro: cidadania é sempre uma conquista do povo. A ampliação dos direitos de cidadania depende da "capacidade política" dos cidadãos, da qualidade participativa desenvolvida. Quarto: as formas de participação decorrem do tipo de sociedade política em que se vive. Quinto: cidadania não se encerra nas suas dimensões da liberdade individual e participação política, mas inclui os direitos sociais e coletivos.

Comun. Inf., v. 2, n. 2, p. 205-228, jul./dez. 1999 
3 Educação para a Cidadania nos Movimentos Sociais

A educação se constitui universalmente "pelo fato de que em todas as sociedades - das comunidades tribais às complexas sociedades urbano-industriais - é necessário garantir não apenas a continuidade biológica, mas, igualmente, a transmissão das normas, dos valores, dos símbolos e das crenças, enfim, da estrutura intermental sem a qual nenhuma sociedade pode funcionar" (Vila Nova, 1995 p.158).

Educação significa educar para a sociedade. É a socialização do patrimônio de conhecimento acumulado, o saber sobre os meios de obter o conhecimento e as formas de convivência social. É também educar para a convivência social e a cidadania, para a tomada de consciência e o exercício dos direitos e deveres do cidadão.

Como diz o professor Sergio Luiz do Amaral Moretti (1999, p.60), "a escola, além de dedicar-se a ensinar os saberes científicos e a habilitar pessoas para a vida profissional, deve ter um objetivo maior, o de preparar as pessoas para o exercício de seus direitos. Dos direitos humanos, direitos de cidadão, ou seja, direitos civis, sociais e políticos".

Contudo, apesar de a escola ${ }^{3}$ ser um espaço privilegiado para tal fim, a preparação para o exercício da cidadania não se aprende só nas carteiras da sala de aula.

Várias instituições compartilham de tal processo formativo, entre elas a família, os meios de comunicação de massa, a igreja, o sindicato, os movimentos sociais e as OGNs - Organizações não Governamentais etc, além das demais relações sociais que o indivíduo participa na vida cotidiana. Os meios de comunicação de massa, especialmente a televisão, têm evidenciado seu potencial e poder de influência na sociedade. Como diz Barros (1997, p.28), "a formação do conhecimento contemporâneo se dá para além da educação formal, numa dinâmica de múltiplas mediações sociais. Expressiva porção de conteúdos assimilados pelas pessoas é absorvida através dos meios de comunicação de massa. Com o crescimento do aparato tecnológico no cotidiano das

Comun. Inf., v. 2, n. 2, p. 205-228, jul./ dez. 1999 


\section{2}

grandes cidades, observa-se uma presença cada vez mais intensa da comunicação na vida das pessoas. Em especial, as novas gerações têm seus valores, opiniões e atitudes sedimentadas por veículos que não se interessam propriamente em sua educação, que não assumem explicitamente seu caráter pedagógico, mas que acabam freqüentemente por influenciar mais profundamente a juventude que a educação desenvolvida na escola. A comunicação coloca-se, assim, no espaço da educação informal, que ocorre nas dinâmicas sociais do dia-a-dia onde o indivíduo se vê em interação com seus pares e com as manifestações culturais e informativas com que se depara".

É no âmbito da educação informal que estaremos enfocando a questão das relações entre comunicação e educação no processo de conquista de cidadania, porém, não a partir do papel da mídia, mas da comunicação que surge em conseqüência da práxis nos movimentos populares, comunitários e das demais organizações que tenham como estratégia a consecução dos interesses coletivos.

Quando falamos em movimentos populares estamos nos referindo ao conjunto de organizações das classes subalternas que são constituídas com objetivos explícitos de tentarem obter um melhor nível de vida através do acesso a bens de consumo individual e coletivo, da garantia da satisfação dos direitos básicos de sobrevivência e dos direitos de participação política na sociedade, como, por exemplo, os serviço de atendimento à doença, a escola em bairros recém-formados, moradia, reforma agrária etc.

Já as OGNs, que são um fenômeno mundial, definem-se como "organizações formais, privadas, porém com fins públicos e sem fins lucrativos, autogovernadas, objetivando realizar mediações de caráter educacional, político, assessoria técnica, prestação de serviços e apoio material e logístico para populações-alvos específicas ou para segmentos da sociedade civil, tendo em vista expandir o poder de participação destas com o objetivo último de desencadear transformações sociais ao nível micro (do cotidiano e/ou local) ou ao nível macro (sistêmico e/ou global)" (Scherer-Warren, apud Gohn, 1997, p.55).

Comun. Inf., v. 2, n. 2, p. 205-228, jul./dez. 1999 
As OGNs não são um fenômeno recente. A expressão "foi criada pela ONU na década de 40 para designar entidades nãooficiais que recebiam ajuda financeira de órgãos públicos para executar projetos de interesse social dentro de uma filosofia de trabalho denominada 'desenvolvimento de comunidade'. (...) Nos anos 90 , as ONGs ganham grande representatividade na sociedade. (...) A esfera básica de atuação das ONGs sempre foi a da sociedade civil. (...) O campo de atuação das ONGs tem sido o do assistencialismo, por meio da filantropia; o do desenvolvimento, por meio de programas de cooperação internacional, entre OGNs e agências de fomento, públicas e privadas; e o campo da cidadania, por meio de ONGs criadas a partir de movimentos sociais que lutam por direitos sociais" (Gohn, 1997, p.54-55).

Os movimentos sociais têm passado por transformações em consonância com as mudanças ocorridas no contexto onde se inserem. Em primeiro lugar, passam de uma fase de manifestações públicas, para uma outra em que se preocupam em constituirem-se enquanto organizações legal e solidamente estruturadas. Depois, sentem a necessidade de uma articulação, a que alguns chamam de "unificação" dos movimentos. É a articulação de entidades e movimentos visando ações conjuntas, seja em nível setorial, municipal, estadual e nacional. Por fim, passam a aceitar participar de parcerias com o setor público e também com instituições privadas, como forma de somar forças e atender as demandas crescentes da sociedade (Peruzzo, 1998 a, p.40-44). Em segundo lugar, eles conseguem fazer que muitas das suas demandas, propostas e ações de cunho social que no início (final dos anos 70 e início dos 80) lhes eram restritas, somadas, é claro, com setores da igreja e ONGs, passassem a ser assumidas por muitos outros atores sociais e pelo conjunto da sociedade. Até algumas empresas privadas, através de programas próprios, apoio a programas de seus funcionários ou a criação de fundações, passam a se engajar em programas de interesse público. A mídia, especialmente a televisão, passa a divulgar mais mensagens procedentes de movimentos sociais e ONGs, a produzir programas

Comun. Inf., v. 2, n. 2, p. 205-228, jul./dez. 1999 


\section{4}

e campanhas de caráter educativo, embora em doses muito pequenas em relação ao tempo destinado a programas convencionais de entretenimento. Cresce a força dos movimentos ambientalistas, que passam a ter mais ressonância e aceitação social. Surge o movimento da Ação da Cidadania Contra a Fome e pela Vida, que mobilizou mais de dois milhões de pessoas em prol da melhoria da qualidade de vida das camadas pobres e miseráveis da população brasileira. "O Brasil é campeão de concentração de renda ${ }^{4}$ e apresenta $15,8 \%{ }^{5}$ da população sem ter acesso às condições mínimas de higiene, saúde e educação" (País entra no ranking..., 1999, p.14), de acordo com dados do relatório de 1999 da ONU- Organização das Nações Unidas. Pela classificação da ONU, o Brasil ocupa a $79^{3}$ posição em desenvolvimento humano, entre 174 países.

Estes são apenas alguns dos indicativos da importância histórica dos movimentos sociais em sua contribuição para alterações no campo da cultura política, por meio da ampliação do espectro da participação política, não só em nível macro do poder político nacional, mas incrementando-a a partir do micro, da participação em nível local, das organizações populares e contribuindo para o processo de democratização e ampliação da conquista de direitos de cidadania.

Verifica-se, pois uma estreita relação entre cultura política, movimentos sociais e cidadania. Cultura política "tradicionalmente é entendida no sentido das relações entre os governantes e governados, nos comportamentos e atitudes que têm uns em relação aos outros, sobretudo no caso dos governados em situação eleitoral, e no caso dos governantes em situação de governo.(...) [Na perspectiva dos movimentos sociais] o conceito se redefine na relação que existe entre os atores sociais e a ordem social, sobretudo subjetivamente"(Galindo Caceres, 1987a, p.7) ${ }^{6}$.

A cultura política se define pela "consciência da relação existente entre o lugar ocupado na organização social e os demais, quer dizer, entre a prática a partir do lugar onde ela se realiza e a totalidade social ou alguns de seus setores. A cultura política ur-

Comun. Inf., v. 2, n. 2, p. 205-228, jul./ dez. 1999 
bana será a que tem esse sentido com respeito à formação urbana específica. A cultura política se define no sentido da práxis, ou seja, a relação entre conhecer e fazer; o conhecimento da própria prática, das práticas dos demais, e a trama dessas práticas de reprodução ou transformação da organização social em sua totalidade ou em algumas de suas partes" (Galindo Cáceres, 1987b, p.133).

Num estudo sobre o movimento comunitário de Vila Velha, Espírito Santo, enquanto sujeito político coletivo, Beatriz S. M. Krohling (1997, p.141-143) mostra que "o processo de redemocratização da sociedade brasileira colocou a ação de sujeitos individuais e coletivos como os protagonistas principais da construção coletiva de direitos de cidadania, abrindo espaço para o reconhecimento público das carências e necessidades produzidas pelas estruturas sociais dominantes e hegemônicas. Nessa perspectiva, (...) [realiza-se um] movimento de negação da tradição autoritária que permeia nossa história social, cujos valores primaram sempre pelo mandonismo das elites e subserviência das camadas mais amplas da sociedade aos desígnios de um Estado centralizador. (...) É inegável a contribuição que os sujeitos coletivos sociais e políticos, dentre eles os movimentos sociais urbanos e rurais, emprestaram ao alargamento do exercício do campo da política e ao processo de redemocratização da sociedade. $\mathrm{Na}$ verdade houve uma redefinição social do poder pela ação desses sujeitos, cujos valores e orientações dirigidos ao campo da política estão sustentados por uma nova sociabilidade, permeada por relações de solidariedade, afetividade, orientações para a vivência comunitária, entre outros. Assim considerados, podemos identificar esses sujeitos portadores de significados, que alteram a cultura política tradicional não obstante seus elementos autoritários e clientelistas ainda estejam presentes em nossa sociedade".

\section{O que significa tudo isso se não o fazer-se cidadão?}

Em sua ação concreta, os referidos movimentos desenvolvem formas próprias de comunicação, como algo engendrado a

Comun. Inf., v. 2, n. 2, p. 205-228, jul./dez. 1999 
partir de toda a ação social transformadora e, ao mesmo tempo, como força intrínseca e propulsora deles próprios. Nesse patamar se desenvolve, simultaneamente, todo um processo educativo, no sentido da educação informal, o que o caracteriza como um dos ambientes propícios para efetivação das relações entre comunicação e educação.

\section{Comunicação e formação para a cidadania}

Torna-se cada vez mais aceita a noção de que a "formação cultural dos seres humanos nas sociedades contemporâneas passa muito pelas intermediações do cotidiano marcadas por um contexto de complexidade. Intermediações que ocorrem através da comunicação interpessoal, grupal e massiva e que se ampliam com a incrementação de novas tecnologias" (Barros, 1997, p.30).

Por sua vez, a educação, entre outras dimensões, implica num educar-se a si mesmo. Como diz Kaplún (1999, p.74), "educarse é envolver-se em um processo de múltiplos fluxos comunicativos. O sistema será tanto mais educativo quanto mais rica for a trama de interações comunicacionais que saiba abrir e por à disposição dos educandos. Uma Comunicação Educativa concebida a partir dessa matriz pedagógica teria como uma de suas funções capitais a provisão de estratégias, meios e métodos destinados a promover o desenvolvimento da competência comunicativa dos sujeitos educandos. Esse desenvolvimento supõe a geração de vias horizontais de interlocução".

Está aí o âmago da questão da educação para cidadania nos movimentos sociais? : na inserção das pessoas num processo de comunicação, onde elas podem tornar-se sujeitos do seu processo de conhecimento, onde elas podem educar-se através de seu engajamento em atividades concretas no seio de novas relações de sociabilidade que tal ambiente permite que sejam construídas.

Tudo isso diz respeito a uma mudança de postura, de uma "cultura do silêncio" das maiorias, como já disse Paulo Freire (1981), ou à cultura da submissão, do cidadão ausente, de um cidadão sem voz, para uma nova cidadania, como esclarece Jesús

Comun. Inf., v. 2, n. 2, p. 205-228, jul./ dez. 1999 
Martín-Barbero (1999). "Diluiram-se, em boa medida, aquelas instituições, aqueles espaços nos quais o cidadão se formava, ao mesmo tempo em que exercia a cidadania. No momento, (...) [existe] uma multiplicidade de movimentos, um pouco tateantes, construindo, por um lado, uma superação, em certa medida do silêncio. Isto é, existe uma insubmissão, uma rebeldia frente ao poder da Igreja, (...) do Estado, (...) da escola... frente a muitos poderes. Tudo o que passa pelos movimentos feministas, pelos movimentos ecológicos, pelos movimentos homossexuais, étnicos, raciais, os movimentos dos negros. (...) Existem elementos de uma nova sociabilidade, uma nova agenda de temas importantes para as pessoas. (...) Estes movimentos, pequenos, em sua maioria inarticulados, à medida que se articulem e articulem a escola, e os meios de comunicação municipais, comunitários, irão criando redes de formação de cidadãos que vão ser muito eficazes, para fazer com que essas vozes dispersas comecem a tomar corpo no espaço regional e, inclusive, no espaço nacional" (Martín-Barbero, 1999 p.7879).

No contexto de tais movimentos, desenvolvem-se experiências de uma comunicação que pode ser denominada de popular ou comunitária, a qual evidencia características próprias, entre elas, o exercício da participação direta. Alí se faz possível que os receptores das mensagens dos meios de comunicação se tornem também produtores das mesmas, se tornem emissores do processo de comunicação.

Parece-nos que neste nível do popular é possível visualizar a concretização, na prática, dos princípios da comunicação horizontal proposta por pensadores da Escola Latino-Americana de Comunicação, como Luís Ramiro Beltrán e Mário Kaplún, que tanto inspiraram experiências de comunicação dos organizados de setores das classes subalternas. Aqui, convém salientar, se insere a proposta das Políticas Democráticas de Comunicação para a América Latina, que emergiu dos calorosos estudos e debates sobre a Nova Ordem Mundial da Informação e Comunicação, nas décadas de 1970 e 1980.

Comun. Inf., v. 2, n. 2, p. 205-228, jul./dez. 1999 


\section{8}

A participação na comunicação é um mecanismo facilitador da ampliação da cidadania, uma vez que possibilita a pessoa tornar-se sujeito de atividades de ação comunitária e dos meios de comunicação ali forjados, o que resulta num processo educativo, sem se estar nos bancos escolares. A pessoa inserida nesse processo tende a mudar o seu modo de ver o mundo e de relacionar-se com ele. Tende a agregar novos elementos à sua cultura.

Os meios de comunicação comunitários/populares - nem todos, obviamente ${ }^{8}$ - têm assim o potencial de serem, ao mesmo tempo, parte de um processo de organização popular ${ }^{9}$ e canais carregados de conteúdos informacionais e culturais, além de possibilitarem a prática da participação direta nos mecanismos de planejamento, produção e gestão. Contribuem, portanto, duplamente, para a construção da cidadania. Oferecem um potencial educativo enquanto processo e também pelo conteúdo das mensagens que transmitem. Por seus conteúdos podem dar vazão à socialização do legado do histórico do conhecimento, facilitar a compreensão das relações sociais, dos mecanismos da estrutura do poder (compreender melhor as coisas da política), dos assuntos públicos do país, esclarecer sobre os direitos da pessoa humana $\mathrm{e}$ discutir os problemas locais. É conhecida a existência, por exemplo, de programas de rádio feitos pelos moradores de favela, em que se faz um trabalho educativo junto às crianças e jovens ensinando sobre os perigos do consumo e do tráfico de drogas. Podem facilitar a valorização das identidades e raizes culturais. Exemplo: dar espaço para manifestações dos saberes e da cultura da população, da história dos antepassados, das lendas às ervas naturais que curam doenças. Servir de canal de expressão aos artistas do lugar, que dificilmente conseguem penetrar na grande mídia regional e nacional. Informar sobre como prevenir doenças, sobre os direitos do consumidor, acesso a serviços públicos gratuitos (registro de nascimento) e tantos outros assuntos de interesse social.

A participação das pessoas na produção e transmissão das mensagens, nos mecanismos de planejamento e na gestão do veí-

Comun. Inf., v. 2, n. 2, p. 205-228, jul./dez. 1999 
culo de comunicação comunitária contribui para que elas se tornem sujeitos, se sintam capazes de fazer aquilo que estão acostumadas a receber pronto, se fazem protagonistas da comunicação e não somente receptores.

Os veículos de comunicação produzidos por setores organizados das classes subalternas, ou a elas organicamente ligados, acabam por criar um campo propício para o desenvolvimento da educação para a cidadania. As relações entre educação e comunicação se explicitam, pois as pessoas envolvidas em tais processos desenvolvem o seu conhecimento e mudam o seu modo de ver e relacionar-se com a sociedade e com o próprio sistema dos meios de comunicação de massa. Apropriam-se das técnicas e de instrumentos tecnológicos de comunicação, adquirem uma visão mais crítica, tanto pelas informações que recebem quanto pelo que aprendem através da vivência, da própria prática. Por exemplo, a seleção de notícias a que a pessoa se vê obrigada a fazer na hora de montar o noticiário na rádio comunitária, bem como os demais mecanismos que condicionam o processo de produzir e transmitir mensagens com os quais se depara cotidianamente, lhe tira a ingenuidade sobre as estratégias e as possibilidades de manipulação de mensagens pelos grandes meios de comunicação de massa. Passa a conhecer as possibilidades de seleção das mensagens, os conflitos de interesses que condicionam a informação ou a programação, a dinâmica do mercado publicitário, além da força que tem um veículo de comunicação, tal como o rádio, o jornal, a televisão etc.

Quanto ao envolvimento em atividades sociais mais amplas, trata-se do engajamento nos movimentos e organizações de interesse público. Estas últimas podem ser, por exemplo, mutirão de limpeza da área verde, as atividades do centro comunitário do bairro, serviço de atendimento à criança carente, curso de preparação profissional etc.

As dimensões do engajamento na dinâmica local, conteúdo das mensagens e da participação em todas as fases do processo comunicativo, em geral, acontecem interligadas e se configuram como o ideal em termos de ação edu-comunicativa no âmbito

Comun. Inf., v. 2, n. 2, p. 205-228, jul./ dez. 1999 


\section{0}

dos movimentos comunitários. No entanto, é sabido que a questão da participação ativa ${ }^{10}$ das pessoas nas várias fases de um processo de comunicação comunitária é algo ainda restrito a um número limitado de experiências. Não obstante, aquelas onde nem todos os três elementos se realizam interligados, também têm o seu valor. A dimensão do conteúdo, mesmo que isolada, lhe assegura certo grau de potencialidade educativa. Exemplo: um programa de televisão ou de rádio, mesmo que não seja produzido com a participação ativa da própria população (através de seus representantes) a quem também se destina o produto final, mas por uma equipe local de moradores, ou até pelos funcionários de uma $O N G$ ou de um sindicato, por exemplo, tem o potencial de contribuir na formação da consciência crítica e ampliação do nível de conhecimento dos emissores e dos receptores.

O potencial educativo envolto nos veículos de comunicação, sejam eles de pequeno ou grande alcance, é muito significativo. Por isso mesmo, são bens públicos e não privados, e representam uma conquista da humanidade enquanto instrumentos capazes de democratizar, de forma ágil, interessante e com fidedignidade, a informação, a cultura e o conhecimento, do senso comum ao científico.

Dentro de todo esse processo de efervescência social, emergem manifestações de comunicação denominadas, inicialmente, de popular ${ }^{11}$ (ou seja, ligada ao povo ou que vem do povo) ou alternativa, no sentido de ser alternativa em relação à grande mídia, no tocante ao conteúdo e aos canais utilizados, tais como boletins, panfletos, alto-falantes etc. Os grandes meios de comunicação de massa, na época, estavam submetidos a mecanismos rígidos de censura e auto-censura, além de seus vínculos políticos e econômicos com os setores das classes dominantes e com o governo, e não refletiam tudo o que estava acontecendo na sociedade (Peruzzo, 1998b, p.144).

As classes populares foram criando seus próprios canais de expressão, como também conquistando espaço nos canais tradicionais de informação para divulgar suas mensagens. Contribuem, assim, para o debate sobre os problemas nacionais e a

Comun. Inf., v. 2, n. 2, p. 205-228, jul./ dez. 1999 
reelaboração das ideologias, valores e modos de ver o mundo, participando na educação para a cidadania. Nessa empreitada contam com a colaboração ou mediação, direta ou indireta, ocasional ou duradoura, de ONGs, Igrejas, Universidades, Fundações, educadores sociais autônomos etc.

Com as transformações ocorridas no país, essas manifestações comunicacionais, se numa perspectiva incorporam suas contribuições à sociedade, por outra também passaram por mudanças. Não podemos esquecer que "o mundo é movimento, mudança constante por força mesmo do que está por vir a ser, do ser do social. Nada é, tudo está sendo, o que hoje é uma força amanhã é outra" (Galindo Cáceres, 1987b, p.95).

Houve, em certo sentido, a superação de uma proposta comunicativa popular/alternativa que não soube abrir-se à sociedade, às mudanças que estavam marcando um novo momento da história e que pretendeu permanecer fechada aos setores combativos $^{12}$. Porém, por volta da metade dos anos 1990 , emergem experiências que transcenderam de práticas comunicativas anteriores, mas se conformaram em processos mais pluralistas, tanto no tocante ao conteúdo quanto ao processo de gestão.

No Brasil, as configurações mais recentes evidenciam um maior uso das tecnologias de comunicação (rádio, televisão, Internet etc.) pelas organizações comunitárias e ONGs, e de um processo crescente de democratização dos meios de comunicação de massa na sociedade. O poder de transmitir mensagens através da mídia, principalmente a de cobertura local e regional, amplia-se a novos emissores. Ao mesmo tempo, a grande mídia também democratiza seu espaço a temáticas de interesse público.

A pressão dos setores populares organizados contribuiu para que a mídia abrisse mais espaço para a transmissão de suas mensagens, bem como para a transmissão de programas produzidos por entidades sem fins lucrativos mais bem estruturadas. No entanto, a própria democratização da sociedade contribuiu para provocar modificações no interior do sistema nacional de comunicação. $\mathrm{O}$ interesse das audiências por temas mais sintonizados

Comun. Inf., v. 2, n. 2, p. 205-228, jul./ dez. 1999 


\section{2}

com as realidades locais faz com que até os grandes meios de comunicação procurem suprir tal demanda oferecendo programas ou cadernos dirigidos a públicos locais ou segmentados. Houve também um crescimento de canais de televisão que têm sua estratégia de programação montada na linha informativa, cultural e educativa. E o caso da TV Futura, TV Senac, Canal Universitário, Canal Comunitário e os canais Legislativos, entre outros, como as próprias TVs Culturas ou TVs Educativas, ligadas aos governos estaduais, que já existem há mais tempo.

Explode também uma quantidade imensa de emissoras de rádios comunitárias (cerca de dez mil) a partir das bases da sociedade. Foi quase como se se dissesse um "basta" à concentração absoluta dos veículos de comunicação de massa nas mãos dos grandes grupos controladores do poder econômico e político e, ao mesmo tempo, um "precisamos do rádio para fazermos programas voltados para o desenvolvimento de nossas comunidades". Associações, grupos comunitários e outras entidades coletivas sem fins lucrativos ${ }^{13}$ começaram a colocar emissoras de rádio no ar, as então chamadas rádios livres comunitárias. Através de muita pressão e lobby conseguem a regulamentação da radiodifusão de baixa potência, através da Lei $9.612 / 98$ e do Decreto 2.615/98. O embate não foi e continua não sendo fácil, pois o Ministério das Comunicações insiste em fechar as emissoras sem autorização para funcionamento, que ele próprio retarda a concessão. Muitas comunidades têm encontrado no Poder Judiciário o amparo legal, através de liminares, para continuarem no ar.

Outra novidade foram os canais comunitários, universitários, legislativos e educativos culturais, no sistema a cabo de televisão, viabilizado pela Lei 8.977/95 e regulamentada pelo decreto 2.206/97. Essa lei resultou dos lances adversos e, por fim, do consenso entre as forças que controlam e regulamentam o uso dos meios de comunicação de massa no país ${ }^{14}$ e o Fórum Nacional pela Democratização da Comunicação. Segmentos sociais até então alijados do poder de transmissão e gestão da mídia, passam a ter o direito de fazê-lo. Apesar de "pegar" as organizações

Comun. Inf., v. 2, n. 2, p. 205-228, jul./ dez. 1999 
desprevenidas, a lei significou um grande avanço na democratização do poder de comunicar.

Portanto, a comunicação popular/comunitária, que inicialmente valeu-se de instrumentos simples, de pequeno alcance e artesanais, aos poucos inspirou a apropriação das tecnologias de comunicação, especialmente o rádio, a televisão e, mais recentemente, a Internet. Porém, tão importante quanto o acesso às tecnologias modernas é o fato de a comunicação comunitária ter sabido adaptar-se à conjuntura da década de 1990 caracterizando-se como espaço mais plural para participação e de respeito às demandas de seus públicos.

Todas essas experiências de democratização dos processos comunicacionais gestaram formas de participação ativa de segmentos da população na elaboração e transmissão da comunicação. É nessa práxis - a prática mais a teorização/reflexão sobre ela - que se desenvolve o processo educativo para a cidadania. Para compreendermos sua dimensão enquanto instrumento educativo para a conquista da cidadania, temos que apanhá-la imbricada nos processos de organização e ação popular mais amplos. Ou seja, no contexto das organizações e movimentos sociais que desencadearam a formação de uma nova cultura política.

Como diz Alfaro Moreno (1998, p.61), ao analisar a comunicação participativa dos anos 70 e 80 , "a vocação educativa da comunicação popular é inquestionável. Não era só um adjetivo mas uma proposta de transformar em sujeitos em contato e participação, recuperando assim os postulados de Paulo Freire. Intimamente ligado ao comunicacional como processo de encontro do sujeito com sua realidade e consigo mesmo, importava promover processos de liberação de maneira pedagógica. Educação que se perfilou como prática de transformação. Certamente, o valor mais recuperável estaria em que se sinalizou que os receptores se educam a si mesmos em contato com a comunicação, tanto em relação com a massiva como com a alternativa. Não era uma questão de ensino ou didática, mas de processos de aprendizagem. Nesse sentido, não pode deixar a comunicação a

Comun. Inf., v. 2, n. 2, p. 205-228, jul./ dez. 1999 
um ritmo espontâneo do encontro com o público, mas que deveria converter-se em todo um trabalho comunicativo de caráter formativo. Dimensão que nem sempre foi praticada com todas suas implicações".

No entanto, manifestações do tipo aqui analisadas não têm sido majoritárias. Entre os desafios para o século XXI, podemos incluir aqueles enumerados por Catalán (1998, p.54): “(...) criar, estabelecer e desenvolver capacidades para produzir, acessar e usar as novas tecnologias de comunicação. Se trata, no fundo, de processos de aquisição de conhecimentos; portanto, de processos de aprendizagem. E de conceber o desenvolvimento, pelo mesmo conceito: como aprendizagem de novas capacidades, instituições e incentivos. Por isso, a cultura - os contextos de aprendizagem - se transforma de agora em diante em um componente central das estratégias de desenvolvimento. Dela dependerá, não só ampliar e aprofundar nossa trama comunicativa, mas também e com ela os processos de participação que consolidam e dinamizam nossas próprias democracias".

No âmago dos processos aqui analisados ocorre um aprendizado que vai ajudando a constituir a cidadania em suas dimensões individual (fortalecimento das liberdades individuais e direitos individuais), política (maior consciência e prática de participação nos órgãos de representação locais ou nacionais) e social (conquista do acesso de benesses relativas a melhores condições de existência). Realiza-se assim uma dinâmica de exercício de direitos e deveres de cidadania, que vai sendo conquistada num processo lento, porém transcendendo os limites do imediato, espraiando valores e esperanças.

\section{Considerações finais}

Parafraseando Paulo Freire ${ }^{15}$, em uma de suas colocações em sala de aula, parece-nos que a frase "comunicação é um ato pedagógico e a educação é um ato comunicativo", sintetiza a complexidade e ao mesmo tempo as inter-relações entre comunicação e educação. Essa cumplicidade entre os dois campos ultra-

Comun. Inf., v. 2, n. 2, p. 205-228, jul./ dez. 1999 
passa as instituições de ensino para penetrar no campo dos grandes meios de comunicação de massa, mas também a comunicação engendrada no contexto das práticas associativas e comunitárias. A escola já não é mais o espaço primordialmente potencializado para educar. Os meios de comunicação passam a compartilhar de tal poder, embora nem sempre o façam no sentido que vá ao encontro do bem-estar comum.

Os meios de comunicação, implementados no contexto das organizações progressistas da sociedade civil, assumem mais claramente um papel educativo, tanto pelo conteúdo de suas mensagens, quanto pelo processo de participação popular que eles podem arregimentar na produção, planejamento e gestão da própria comunicação. A participação popular é algo construído dentro de uma dinâmica de engajamento social mais amplo, em prol do desenvolvimento social e que tem o potencial de, uma vez efetivada, ajudar a mexer com a cultura, a construir e reconstruir valores, contribuir para maior consciência dos direitos humanos fundamentais e dos direitos de cidadania, a compreender melhor o mundo e o funcionamento dos próprios meios de comunicação de massa. Revelam-se, assim, como espaço de aprendizado das pessoas para o exercício de seus direitos e a ampliação da cidadania.

\section{Abstract}

The text is about the edu-communication forged in a process of informal education and in the context of the organizations and popular movements. We conclude that, in practice, with own characteristics, among them the one about the active participation and the contents related to the local realities, the communication produced by organized subordinate sections has been contributing to enlarge the educational spectrum around the exercise of the citizenship.

Key words: communication and education; popular movements; communication and citizenship.

Comun. Inf., v. 2, n. 2, p. 205-228, jul./dez. 1999 


\section{Notas}

1. Parte do que segue sobre a temática da cidadania foi transcrita, com pequenas modificaçōes, do texto da própria autora (Peruzzo, 1998a, p.283-286).

2. Praça onde se reuniam os cidadãos para debater os assuntos da cidade.

3. Escola aqui é entendida em sentido amplo envolvendo também a universidade.

4. Os $20 \%$ mais pobres consomem $2,5 \%$ da renda, enquanto os $20 \%$ mais ricos detêm $63,4 \%$ da população. Aos outros $60 \%$ intermediá-rios cabem $34,1 \%$ da renda nacional.

5. 26 milhões de pessoas.

6. As citações de autores estrangeiros foram por nós traduzidas.

7. Como também em outros espaços.

8. Uma vez que muitos dos quais atuam numa linha de reprodução, em escala local ou comunitária, da estrutura e objetivos mercadológicos da grande mídia privada, ou servem ao proselitismo político ou religioso.

9. Por exemplo, o engajamento em movimentos de interesse coletivo, tais como um mutirão de limpeza da área verde, atividades do centro comunitário do bairro, um serviço de atendimento à criança carente, um curso de preparação profissional etc.

10. Participação ativa e ampliada da população é coisa que se constrói lentamente, na própria dinâmica social, em função das condições encontradas e conforme a ampliação do compromisso das pessoas com a própria cidadania. Ver Peruzzo (1998a). 1998b.

11. Ver aprofundamento sobre esta temática em Peruzzo, 1998a,

12. Ver análise de Alfaro Moreno, Rosa Maria (1998) sobre as distorções ocorridas na comunicação popular, bem como faz indicações para uma comunicação cidadã para uma sociedade justa e solidária.

13. Na verdade não foram só entidades sem fins lucrativos que criaram rádios comunitárias, mas também indivíduos isolados ou grupos o fizeram, tanto por objetivos comerciais quanto político-partidários. Há também um grande número de emissoras ligadas a igrejas e seitas religiosas.

14. Proprietários dos meios de comunicação de massa, Governo e representantes do Poder Legislativo.

15. Ao dizer: todo ato educativo é um ato político e todo ato político é um ato educativo.

Comun. Inf., v. 2, n. 2, p. 205-228, jul./dez. 1999 


\section{Referências Bibliográficas}

ABRANCHES, Sérgio H. Nem cidadãos, nem seres livres: o dilema político do indivíduo na ordem liberal-democrática. Dados - Revista de Ciências Sociais, Rio de Janeiro: IUPERJ, n.28, p.5.25, 1985.

ALFARO MORENO, Rosa Maria. Culturas populares y comunicación participativa: en la ruta de las redefiniciones. In: Participación social en los medios masivos? - canales regionales y sociedades urbanas. Bogotá: Centro Cultural Minuto de Dios, nov. 1998. p.58-76. (Memórias: Foro Internacional).

ALVES, Luis Roberto. Educação, cultura e cidadania: comunicações da periferia. Comunicafãa \& Educafãa. São Paulo: ECA-USP/Ed. Moderna, n. 15. p. 35-44. mai./ago.1999.

BARBALET, J.M. A cidadania. Lisboa: Estampa, 1989.

BARROS, Laan Mendes de. Comunicação e educação numa perspectiva plural e dialética. Nexos - Revista de Estudos de Educafão e Comunicaf̧ão. São Paulo: Univ. Anhembi-Morumbi, p.19-38, jul./dez. 1997.

CATALÁN B., Carlos. Medios de comunicación y participación: el caso de Chile. In: Participación social en los medios masivos? - canales regionales y sociedades urbanas. Bogotá: Centro Cultural Minuto de Dios, nov. 1998. p.41-57. (Memórias: Foro Internacional).

FREIRE, Paulo. A educação como prática da liberdade. Rio de Janeiro: Paz e Terra, 1981.

GALINDO CÁCERES, Luis Jesus. Movimiento social y cultura politica: discurso, conciencia, historia... Mexico: Universidad de Colima, 1987a.

GALINDO CÁCERES, Luis Jesus. Organización social y comunicación. Mexico: Premiá, 1987b.

GOHN, Maria da Glória. Os sem-terra, ONGs e cidadania. São Paulo: Cortez, 1997.

KAPLÚN, Mário. Processos educativos e canais de comunicação. Comunicafão \& Educaf̧ão. São Paulo: Eca-Usp/Moderna, p.68-75jan., abr.de 1999.

KROHLING, Beatriz S. Martins. Conselho comunitário de Vila Velha-ES: um sujeito coletivo político em movimento. São Paulo: Pontificia Universidade Católica, 1997. (Tese de Doutorado - Serviço Social).

MARSHALL, T.H. Cidadania, classe social e status. Rio de Janeiro: Zahar, 1967.

MARTÍN-BARBERO, Jesús. Sujeito, comunicação e cultura. Comunicafão \& Educaf̧ão. São Paulo: Eca-Usp/Moderna, n.15, maio/ago. 1999. (Entrevista concedida a Roseli Fígaro e Maria Aparecida Baccega).

Comun. Inf., v. 2, n. 2, p. 205-228, jul./ deq. 1999 


\section{8}

MORETTI, Sergio L. Amaral. A escola e o desafio da modernidade. Revista ESPM. São Paulo, v.6, jan./fev.1999.

PAÍS entra no ranking que mede a pobreza. Folha de S. Paulo, 11 jul.1999, p.14.

PERUZZO, Cicilia M.K. Comunicafão nos movimentos populares: a participação na construção da cidadania. Petrópolis: Vozes, 1998a.

PERUZZO, Cicilia M.K. Mídia comunitária. Comunicą̧ão \& Sociedade. São Bernardo do Campo: UMESP, n.30, p.141-156, 1998.

SOARES, Ismar. Sociedade da informafão ou da comunicafãa? São Paulo: Cidade Nova, 1996.

VILA NOVA, Sebastiào. Introdução à sociologia. São Paulo: Atlas, 1995. 